\title{
Doses de Nitrogênio e Enxofre na Produção e Qualidade da Forragem de Campo Natural de Planossolo no Rio Grande do Sul ${ }^{1}$
}

\author{
Marcelo Könsgen Cunha ${ }^{2}$, Lotar Siewerdt ${ }^{3}$, Paulo Silveira Júnior ${ }^{4}$, Frank Siewerdt ${ }^{5}$
}

\begin{abstract}
RESUMO - Foram avaliados os efeitos da fertilização nitrogenada e sulfurada sobre a produção de matéria seca (MS) e o teor de proteína bruta (PB) da forragem de um campo natural em Planossolo, entre outubro de 1996 e março de 1997, na área experimental de Pastagens da UFPEL, no Capão do Leão-RS. Os tratamentos consistiram de seis doses de enxofre (S) (0, 10, 20, 30, 40 e 50 kg/ha) sob a forma de sulfato de amônio e quatro doses de nitrogênio (N) (50,100,150 e $200 \mathrm{~kg} / \mathrm{ha}$ ), sob a forma de uréia e sulfato de amônio, arranjadas num fatorial completo de blocos casualisados, com quatro repetições. A fertilização foi a lanço, em cobertura, sem parcelamento, em 08/10/96. Foram realizados dois cortes, em 03/12/96 e 14/03/97, utilizando-se segadeira mecânica tipo barra horizontal com altura de corte de 3 centímetros. A produção de MS e o teor de PB aumentaram com o incremento das doses de N e S. Nas variáveis analisadas não houve interação entre as doses de $\mathrm{N}$ e S. A dose de enxofre de $35 \mathrm{~kg} / \mathrm{ha}$ é suficiente para maximizar a produção de MS. Já a dose de $200 \mathrm{~kg} / \mathrm{ha}$ de N não foi suficiente para determinar a máxima produção de MS. Doses de nitrogênio de até $200 \mathrm{~kg} / \mathrm{ha}$ e de enxofre até $50 \mathrm{~kg} / \mathrm{ha}$, não foram suficientes para determinar o máximo teor de PB na forragem.
\end{abstract}

Palavras-chave: campo natural, fertilização nitrogenada, fertilização sulfurada, forrageiras

\section{Effect of Nitrogen and Sulfur Levels on Yield and Quality Forage in a Native Low-Land Pasture Area in Southern Brazil}

\begin{abstract}
Nitrogen and sulfur fertilizations were evaluated in a native low-land pasture area (Planossolo) in southern Brazil, state of Rio Grande do Sul, for dry matter yield and crude protein contents, between Oct. 1996 and Mar. 1997. In a factorial treatment arrangement six levels of sulfur $(0,10,20,30,40$ and $50 \mathrm{~kg} / \mathrm{ha})$ were combined with four levels of nitrogen $(50,100$, 150 and $200 \mathrm{~kg} / \mathrm{ha}$ ) topdressed to the pasture in Oct. 10, 1996. Two cuttings were made to determine dry matter yield and crude protein contents (Dec. 3, 1996 and Mar. 14, 1997). Results indicate that both factors increase the dry matter yield and crude protein contents on forage. With $35 \mathrm{~kg} / \mathrm{ha}$ of sulfur was obtained the maximum dry matter yield. However at level of $200 \mathrm{~kg} / \mathrm{ha}$ of nitrogen was not enough to obtain maximum dry matter yield. At levels of $200 \mathrm{~kg} / \mathrm{ha}$ of nitrogen and $50 \mathrm{~kg} / \mathrm{ha}$ of sulfur was not enough to obtain the maximum crude protein contents.
\end{abstract}

Key Words: forage, native pasture, nitrogen fertilization, sulfur fertilization

\section{Introdução}

A exploração de rebanhos pecuários constitui-se em uma atividade primária importante para a economia do Rio Grande do Sul, a qual se desenvolve em áreas de pastagens naturais que cobrem uma extensão aproximada de 12 milhões de hectares, constituindo o principal recurso forrageiro disponível para a produção animal neste estado. É fato conhecido que estas têm uma estacionalidade de produção a qual determina que animais criados extensivamente, durante todo o ano sobre essas pastagens, enfrentem um período de excesso de oferta de forragem (primavera - verão) e um período de escassez (outono - inverno), já que a maioria dos estabelecimentos lota suas pastagens de acordo com o período de menor oferta forrageira, determinando-se, portanto, lotação média de $0,5 \mathrm{UA} / \mathrm{ha} /$ ano (para o rebanho bovino). Os rebanhos criados sem nenhuma estratégia de forrageamento para a época crítica do crescimento das pastagens naturais apresentam baixa eficiência, traduzida, no rebanho bovino, por baixa taxa de desfrute, consequiência de elevada idade de abate do novilho, alta idade de entoure, prolongado intervalo entre partos, baixa taxa de natalidade anual, elevada taxa de mortalidade e baixa produtividade de carne

\footnotetext{
1 Parte da tese de mestrado do primeiro autor, financiado por CAPES.

2 Engo. Agro., M.Sc.

3 Engo. Agro., M.Sc., Ph.D., Prof. Titular do Departamento de Zootecnia da UFPEL.

4 Eng-. Agro-, M Sc., Prof. Titular do Departamento de Matemática, Estatística e Computação da UFPEL.

5 Engo. Agro., M Sc., Ph.D. Prof. Adjunto do Departamento de Matemática, Estatística e Computação da UFPEL.
} 
por hectare por ano. Entre as opções para tal período, tem-se a adubação das pastagens nativas, visando a fenação do excedente de forragem produzida nestas pastagens para o fornecimento deste feno na época crítica do crescimento das pastagens. O potencial de produção e a qualidade da forragem dessas pastagens ainda não estão completamente determinados. É possível, por meio de adubações, aumentar a quantidade e melhorar a qualidade da forragem (feno) dessas pastagens.

MALAVOLTA (1979) relata que o fator de maior importância, depois do clima, para a produção de matéria seca é a disponibilidade do nitrogênio. Tem-se demonstrado que, mediante a fertilização com esse elemento, é possível elevar a produção de matéria seca e alcançar níveis impossíveis de serem obtidos com qualquer outro manejo. Numerosos autores têm observado esse comportamento e, em geral, têm determinado que a resposta é linear até doses de $350 \mathrm{~kg} / \mathrm{ha}$ do nutriente. (Ramage et al., 1958; Cowling, 1961; Albuquerque, 1962; Castle e Reid, 1963; Vera,1964; Cowling e Lockyer, 1965; Cowling, 1966; Brockman, 1966, citados por CARAMBULA, 1977). Esses autores observaram também que, para cada incremento na dose de nitrogênio, se produz um aumento na produtividade de matéria seca e o mesmo é percentualmente menor, à medida que a dose do fertilizante aumenta, até que, em doses superiores a $500 \mathrm{~kg} / \mathrm{ha}$ de $\mathrm{N}$, as produtividades alcancem nível máximo e se estabilizam (Ramage et al., 1958; Schmidt e Tenpas, 1965; Cowling, 1966; Reid, 1966, citados por CARAMBULA, 1977).

Dos dados registrados em treze experimentos realizados sob diferentes condições e espécies, Davies e Williams (1958), citados por CARAMBULA (1977), concluíram que a média de matéria seca produzida por kg de $\mathrm{N}$ utilizado alcança $10 \mathrm{~kg}$. Em outro estudo, COWLING e LOCKER (1965), encontraram, na média das espécies estudadas, uma resposta de 20 a $30 \mathrm{~kg}$ de MS para doses de, aproximadamente, $180 \mathrm{~kg}$ de N/ha e de 14 a $23 \mathrm{~kg}$ de MS para doses de $380 \mathrm{~kg}$ de $\mathrm{N} / \mathrm{h}$. A produção de matéria seca em resposta à adubação nitrogenada é, normalmente, linear dentro de certos limites, que variam principalmente com o potencial genético das diferentes espécies, a freqüência de cortes e as condições climáticas (BOIN, 1986). TEIXEIRA (1995), trabalhando em campo natural de Planossolo, com doses de até $250 \mathrm{~kg} / \mathrm{ha}$ de $\mathrm{N}$, concluiu que a produção de matéria seca, assim como o teor de proteína bruta, apresentou resposta linear até a dose de $250 \mathrm{~kg} / \mathrm{ha}$ de $\mathrm{N}$. Entretanto,
NUNES (1995) e LAJÚS (1995), também trabalhando no mesmo local, concluíram que aquela pastagem natural atinge rendimento máximo de matéria seca com doses entre 400 e $500 \mathrm{~kg} / \mathrm{ha}$ de $\mathrm{N}$ e o teor de proteína bruta da forragem aumenta com doses crescentes de nitrogênio.

O conteúdo protéico também aumenta com o incremento da disponibilidade de nitrogênio. Porém, conforme REID (1966), os máximos rendimentos de proteína são alcançados com doses de nitrogênio maiores que aquelas necessárias para produzir os rendimentos mais altos em matéria seca. É importante destacar que o conteúdo protéico tem influência na digestibilidade e no consumo voluntário das forragens.

O enxofre é um elemento importante no metabolismo dos mamíferos, porque os aminoácidos sulfurados são parte intrínseca da maioria das proteínas dos tecidos e sulfatos e seus ésteres são encontrados em muitos tecidos e metabólitos (SIEBERT e VIJCHULATA, 1983). Esse elemento tem por função ser grupo ativo de enzimas e coenzimas, sendo também componente de coenzimas (MALAVOLTA, 1979). Plantas deficientes em enxofre (S) têm a sua síntese de proteínas interrompida, já que esse elemento participa de dois aminoácidos essenciais, a cistina e a metionina, e com isto o crescimento é retardado (RAIJ, 1991). O enxofre é componente do acetil-CoA, composto que representa o "centro nervoso" do ciclo de Krebs, influenciando, portanto, todo o metabolismo de gordura e de carboidratos. Participam da composição das ferredoxinas complexos enzimáticos envolvidos na fotossíntese e na fixação do $\mathrm{N}_{2}$ (em leguminosas) e na formação da clorofila. TISDALE (1977) afirma que o nível de clorofila aumenta nas plantas sob fertilizações sulfuradas e ocorre redução na fotossíntese, em virtude dos baixos conteúdos de clorofila, os quais eram devidos à deficiência de enxofre. Boa parte das plantas desenvolvidas em solos da América Tropical é deficiente em enxofre, sendo essa mais comum nos solos arenosos, com baixos teores de matéria orgânica. Isto se deve ao fato de que o teor total de $\mathrm{S}$ no solo se encontra bastante correlacionado com os teores de matéria orgânica e $\mathrm{N}$, indicando que a maior porção de $\mathrm{S}$ aparece ligado ou associado à matéria orgânica (MASCARENHAS, 1977).

MONTEIRO (1986) desenvolveu uma série de experimentos de campo e em casa de vegetação, para testar a fertilização com S. Foi usado um Spodosol que vinha suportando uma consorciação de trevo branco (Trifolium repens L.) com pensacola 
(Paspalum notatum Flugge) por um período aproximado de trinta anos. Na casa de vegetação, o desenvolvimento do trevo branco dependeu da fertilização com S, tendo sido aumentadas a produção de matéria seca, as concentrações de $\mathrm{N}$ e $\mathrm{S}$ e as quantidades de $\mathrm{N}$ e $\mathrm{S}$ na planta, à medida que se incrementava a dose de S. No campo, a referida fertilização aumentou anualmente a produção de matéria seca e as quantidades de $\mathrm{N}$ e $\mathrm{S}$ em ambas as forrageiras. O trevo branco teve sua concentração de $\mathrm{S}$ elevada, em função das fertilizações sulfuradas.

Harris, Schoroder e Gilman (1968), citados por WILKINSON e LANGDALE, (1974), verificaram que a produção de pensacola (Paspalum notatum Flugge) em vasos com areia fina sem enxofre foi de $70 \%$ daquela com enxofre. Houve aumento no conteúdo de nitrogênio e proteína na planta com a utilização da fertilização sulfurada. Sorenson et al. (1968), citados por GRIFFITH (1974), concluíram que tanto a concentração de nitrogênio, como a produção de matéria seca, aumentaram com $67 \mathrm{~kg} / \mathrm{ha}$ de $\mathrm{S}$.

Em recente estudo, BITENCOURT JÚNIOR (1995), trabalhando com doses de fósforo, potássio, calcário e suas interações na produção e qualidade da forragem de pastagens nativas de Planossolo, em Pelotas-RS, concluiu que o teor médio de enxofre encontrado na matéria seca daquela forragem é insuficiente para suprir as quantidades requeridas para dieta de mantença dos ruminantes. Outro fator que evidencia a necessidade da fertilização sulfurada é o fato de que, nas pastagens nativas do Rio Grande do Sul, práticas como calagem e adubação fosfatada, geralmente recomendadas para melhoramentos de pastagens nativas, têm como resultado o aumento do pH e da concentração de fosfatos na camada arável, que, auxiliados pelo maior teor de matéria orgânica existente na camada arável dos solos, RAIJ (1991), fazem com que a permanência da maior parte do enxofre na forma de $\mathrm{SO}_{4}{ }^{-2}$ (que é a forma na qual o enxofre é absorvido pelas plantas) contido naquela camada seja dificultada, podendo assim o $\mathrm{SO}_{4}{ }^{-2}$ ser acumulado no subsolo, o que é fato conhecido, em solos de regiões tropicais úmidas (Fox e Blair, 1973, citado por RAIJ, 1991). Portanto, o enxofre só estará disponível às plantas, na ocorrência da situação acima citada, se as raízes atingirem a profundidade na qual ele se encontra.

É importante destacar que não há um parâmetro para determinar o uso ou não da fertilização sulfurada nos solos do Rio Grande do Sul, já que as faixas de interpretação para o $\mathrm{S}$, de acordo com dados de análise de solo, apresentadas pela COMISSÃO DE FERTILIDADE DO SOLO-RS/SC (1994), indicam somente a probabilidade de resposta das culturas à aplicação do nutriente. Assim um valor "baixo" na interpretação da análise indica que a probabilidade de se obter aumento de rendimento, pela aplicação do nutriente, é maior do que em um solo enquadrado na faixa "suficiente". Daí depreende-se que, mesmo num solo enquadrado na faixa "suficiente" quanto ao enxofre, podem-se esperar respostas à aplicações de enxofre ao solo.

Cabe lembrar que o uso de adubos que contêm $\mathrm{S}$ está diretamente relacionado com o uso eficiente do $\mathrm{N}$, uma vez que, além da conhecida influência da lei do mínimo na produtividade agrícola, o $\mathrm{N}$ e o $\mathrm{S}$ exercem funções tão relacionadas na vida da planta que, muitas vezes, é possível definir-se o estado nutricional da planta com base na relação dos teores desses dois elementos na matéria seca. A relação $\mathrm{N}: \mathrm{S}$ da adubação influencia a resposta das plantas, sendo que, ao se elevar a dose de $\mathrm{N}$ na adubação, é necessário aumentar a dose de $\mathrm{S}$, correspondentemente, para se garantir o equilíbrio desses nutrientes dentro da planta e obter-se, desse modo, melhor resposta por parte das plantas. Muitas vezes não há respostas para doses mais elevadas de $\mathrm{S}$, pelo fato de o nível N na adubação não acompanhar este aumento (VITTI, 1986). Segundo PUPO (1979), pode ocorrer exatamente o contrário, ou seja, devido à falta de $\mathrm{S}$ (ou outro nutriente) no solo, não é observada resposta à doses mais altas de $\mathrm{N}$, fato na verdade mais comum de ser encontrado no meio rural. WERNER e MONTEIRO (1988) também concluem que a inclusão de uma fonte de $\mathrm{S}$ na formulação da adubação deve ser considerada, a fim de evitar que a deficiência de $\mathrm{S}$ restrinja os resultados positivos que a adubação proporciona.

Este trabalho foi conduzido de forma a determinar a produção e a qualidade da forragem de um campo natural em Planossolo, quando submetido a diferentes combinações de doses de nitrogênio e enxofre.

\section{Material e Métodos}

O experimento foi realizado na área experimental de pastagens pertencente à UFPEL, localizada no município do Capão do Leão (RS). O solo da área experimental pertence à unidade de mapeamento Pelotas, classificado como Planossolo Solódico (IBGE, 1986) de textura argilosa, relevo plano, substrato sedimentos de granito, ácido e com médios teores de 
matéria orgânica. A principal limitação destes solos diz respeito à má drenagem, conseqüência de um horizonte B impermeável. A análise de solo na área experimental revelou as seguintes características: pH- 4,7; P- $12,4 \mathrm{mg} / \mathrm{dm}^{3}$; K- $51 \mathrm{mg} / \mathrm{dm}^{3}$; Al- 18 $\mathrm{Mmol}_{\mathrm{c}} / \mathrm{dm}^{3} ; \mathrm{Ca}-17 \mathrm{Mmol}_{\mathrm{c}} / \mathrm{dm}^{3} ; \mathrm{Mg}-8 \mathrm{Mmol}_{\mathrm{c}} / \mathrm{dm}^{3}$; argila- $140 \mathrm{~g} / \mathrm{kg}$; MO- 29,8 g/l; e Na- $34 \mathrm{mg} / \mathrm{dm}^{3}$.

$\mathrm{O}$ delineamento experimental consistiu em um esquema de blocos casualizados com 24 tratamentos e quatro repetições, com os tratamentos arranjados em um fatorial completo do tipo $6 \times 4$, em que ambos os fatores, enxofre $(\mathrm{S})$ e nitrogênio $(\mathrm{N})$, são quantitativos. Os níveis de enxofre foram 0, 10, 20, 30, 40 e $50 \mathrm{~kg} / \mathrm{ha} \mathrm{de} \mathrm{S.} \mathrm{Os} \mathrm{níveis} \mathrm{de} \mathrm{nitrogênio} \mathrm{foram} \mathrm{50,} \mathrm{100,}$ 150 e $200 \mathrm{~kg} / \mathrm{ha}$ de $\mathrm{N}$. As parcelas experimentais tinham uma área de $28 \mathrm{~m}^{2}$ (7 m x $\left.4 \mathrm{~m}\right)$.

O experimento foi realizado no período de setembro de 1996 a março de 1997, sendo feita, em setembro de 1996, uma roçada mecânica em toda a área experimental, para fins de uniformização do campo antes da aplicação das doses de nitrogênio e enxofre, que ocorreu em 08/10/96. Essa aplicação foi feita a lanço, em cobertura, de forma manual e sem parcelamento da dose, sendo usados os adubos sulfato de amônio e uréia.

Posteriormente, foram feitos dois cortes para avaliar a produção e a qualidade da forragem, sendo o primeiro em 03/12/96 (56 dias após a aplicação da adubo) e o segundo em 14/03/97 (99 dias após o primeiro corte). Os cortes foram realizados quando as plantas apresentaram desenvolvimento suficiente que justificasse a realização de corte, visando a produção de feno, ou seja, quando as plantas tinham, no mínimo, $25 \mathrm{~cm}$ de altura. Para a realização desses cortes, foi usada uma segadeira mecânica do tipo "barra horizontal". A vegetação das parcelas experimentais foi ceifada a uma altura média de $3 \mathrm{~cm}$ acima do nível do solo. No momento dos cortes, uma área útil de $7 \mathrm{~m}^{2}$ por parcela foi ceifada para avaliação da produção de forragem. Após o corte, a forragem dessa área útil foi imediatamente recolhida e pesada no campo para a determinação da produtividade de matéria verde (MV), em $\mathrm{kg} \mathrm{MV} / 7 \mathrm{~m}^{2}$, retirando-se uma amostra representativa da mesma, aproximadamente $0,75 \mathrm{~kg}$, para futuras determinações laboratoriais.

No Laboratório de Pastagens do Departamento de Zootecnia da FAEM - UFPel, a amostra de forragem verde proveniente da área experimental foi pesada (no mesmo dia do corte) e, logo depois, feita a secagem em estufa com circulação forçada de ar a $65-70^{\circ} \mathrm{C}$, até peso constante. Após a secagem, as amostras foram retiradas da estufa e pesadas. Com o peso antes e após a secagem da forragem, pode-se calcular o teor de matéria seca da forragem (\%MS). De posse desse teor e da produção de MV, calculou-se a produção da matéria seca (MS). As amostras secas foram moídas em moinho tipo Willey (mecha $2 \mathrm{~mm}$ ), acondicionadas em sacos plásticos e convenientemente armazenadas até a determinação do teor de nitrogênio total contido na forragem $(\% \mathrm{~N})$.

A determinação do teor de $\mathrm{N}$ total da forragem foi feita no Laboratório de Nutrição Animal do Departamento de Zootecnia da FAEM - UFPel, utilizando-se o método Microkjeldahl, sendo o teor de proteína bruta da forragem (\% PB) calculado pela fórmula: $\% \mathrm{~PB}=\% \mathrm{~N} \times 6,25$.

As análises estatísticas foram feitas por intermédio do programa SANEST (ZONTA e MACHADO, 1984), tendo sido analisadas as seguintes variáveis: (a) produção de MS (kg de MS/ha); (b) teor de PB na MS(\%).

\section{Resultados e Discussão}

Os resultados apresentados e discutidos a seguir referem-se à produção de matéria seca e ao teor de proteína bruta na matéria seca. Para os teores de proteína bruta os resultados foram analisados por corte. Já para a produção de matéria seca, as análises foram feitas com base na soma da produção dos dois cortes.

No campo natural onde foi conduzido o experimento, foram identificadas espécies forrageiras pertencentes à família Gramineae dos seguintes gêneros: Paspalum, Axonopus, Andropogon, Eragrostis, Briza, Ischaemum e Piptochaetium. Porém, predominavam na área espécies de Axonopus, seguidas de espécies de Paspalum, sendo que espécies dos demais gêneros ocorriam com menor freqüência na área. Pertencente à família botânica Leguminosae, foram identificadas espécies forrageiras do gênero Medicago, as quais ocorriam com razoável freqüência. Havia a ocorrência, com frequiência escassa, de espécies vegetais de outras famílias botânicas, entre elas: Compositae, Plantaginaceae, Solanaceae, Umbelliferae, Verbenaceae e Cyperaceae.

Para a produtividade total de matéria seca (Tabela 1), a análise de variância acusou significância apenas para os fatores principais, enxofre $(\mathrm{P}<0,05)$ e nitrogênio $(\mathrm{P}<0,001)$, obtendo-se uma média geral de $4.516,08 \mathrm{~kg} / \mathrm{ha}$ de MS e CV=11,54\%. A análise de regressão polinomial para os níveis de enxofre acusou significância para o efeito quadrático com a equação 
Tabela 1 - Produções médias totais de matéria seca, em $\mathrm{kg} / \mathrm{ha}$, do campo natural nas diferentes doses de $\mathrm{N}$ e $\mathrm{S}$ Table 1 - Average dry matter yield $(\mathrm{kg} / \mathrm{ha}$ ) on different levels of $N$ and $S$

\begin{tabular}{|c|c|c|c|c|c|c|c|}
\hline \multirow[t]{2}{*}{$\mathrm{N}(\mathrm{kg} / \mathrm{ha})$} & \multicolumn{6}{|c|}{$\mathrm{S}$ (kg/ha) } & \multirow[b]{2}{*}{$\begin{array}{c}\text { Média } \\
\text { Mean }\end{array}$} \\
\hline & 0 & 10 & 20 & 30 & 40 & 50 & \\
\hline 50 & 3343 & 3596 & 3747 & 4053 & 3733 & 3858 & 3722 \\
\hline 100 & 4231 & 4103 & 4655 & 5138 & 4366 & 4545 & 4506 \\
\hline 150 & 4244 & 4659 & 4542 & 5282 & 4644 & 4735 & 4684 \\
\hline 200 & 4830 & 5211 & 5476 & 4675 & 5472 & 5253 & 5153 \\
\hline $\begin{array}{l}\text { Média } \\
\text { Mean }\end{array}$ & 4162 & 4392 & 4605 & 4787 & 4554 & 4598 & 4516 \\
\hline
\end{tabular}

de regressão $\mathrm{Y}=4.151,227679+32,3620089 \mathrm{X}-$ $0,48457589 \mathrm{X}^{2}\left(\mathrm{R}^{2}=0,88\right)$ (Figura 1) e para os níveis de nitrogênio acusou significância para o efeito linear com a seguinte equação de regressão $\mathrm{Y}=3.398,541667$ $+8,9403333 \mathrm{X}\left(\mathrm{R}^{2}=0,94\right)$ (Figura 2). Com estes resultados, observa-se que o campo natural de Planossolo responde positivamente em termos de produtividade de matéria seca, quando adubado com nitrogênio ou enxofre, no início da primavera. Observa-se também que a produtividade de matéria seca atinge o ponto de máxima na dose de $33,4 \mathrm{~kg} / \mathrm{ha}$ de $\mathrm{S}$, a partir da qual a produtividade tende a diminuir, indicando que nesta dose de enxofre se obteve a maior produtividade de MS. Contudo, a produtividade pode ter sido limitada por outro nutriente, de forma que, trabalhando com uma adubação mais equilibrada, poder-se-iam ter aumentos na produtividade de matéria seca mesmo com maiores doses de enxofre. Para o nitrogênio não se obteve o ponto de máxima produtividade de matéria seca de forragem neste

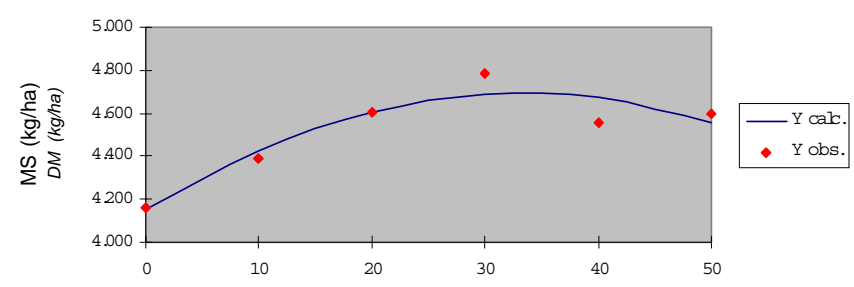

Doses de enxofre $(\mathrm{kg} / \mathrm{ha})$ Levels of sulfur ( $\mathrm{kg} / \mathrm{ha}$ )

Figura 1 - Produção de matéria seca do campo nativo, em função das doses de enxofre.

Figure 1 - Dry matter yield according to levels of sulfur. experimento, já que a resposta foi linear para as doses de $\mathrm{N}$ aplicadas. Isto está de acordo com os dados de diversos autores, entre eles CARAMBULA (1977) e NUNES (1996), confirmando que o campo natural pode ainda ser mais produtivo, quando adubado com níveis mais elevados de $\mathrm{N}$ que os usados neste experimento. Efetivamente, NUNES (1996), testando doses de 0 a $700 \mathrm{~kg} / \mathrm{ha}$ de $\mathrm{N}$, em campo natural de Planossolo, obteve resposta quadrática às doses de $\mathrm{N}$ utilizadas, representada pela equação $\mathrm{Y}=5813,62+$ $22,2721 \mathrm{X}-0,0245806 \mathrm{X}^{2}\left(\mathrm{R}^{2}=0,89\right)$, determinando o ponto de máxima resposta com $453 \mathrm{~kg} / \mathrm{ha}$ de N. Por outro lado, LAJÚS (1997), repetiu o mesmo experimento por mais um ano com as mesmas doses de $\mathrm{N}$, realizando, porém, uma adubação de reposição com $90 \mathrm{~kg} / \mathrm{ha}$ de $\mathrm{P}_{2} \mathrm{O}_{5}$ e $60 \mathrm{~kg} / \mathrm{ha}$ de $\mathrm{K}_{2} \mathrm{O}$. No segundo ano, o autor obteve o ponto de máxima produtividade com a dose de $684 \mathrm{~kg} / \mathrm{ha}$ de $\mathrm{N}$, representada pela equação $\mathrm{Y}=4.289,541667+21,8721726 \mathrm{X}$ $0,01627887 X^{2}\left(R^{2}=0,99\right)$. SILVA (1997) repetiu por

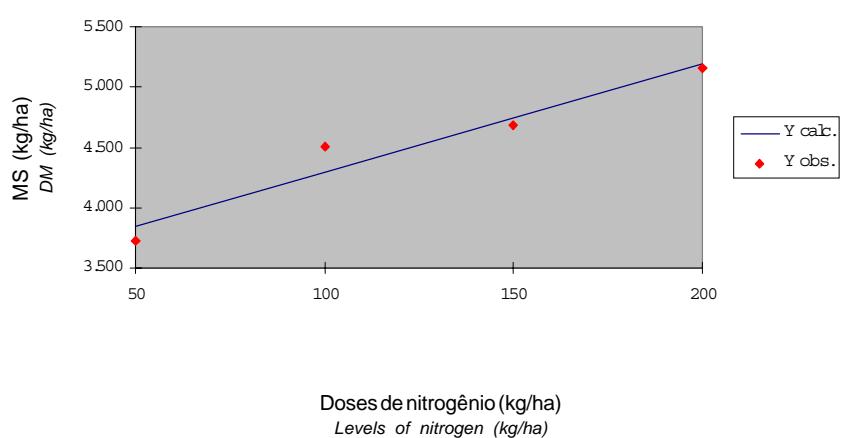

Figura 2 - Produção de matéria seca do campo nativo, em função das doses de nitrogênio.

Figure 2 - Dry matter yield according to levels of nitrogen. 
mais um ano o mesmo experimento em condições idênticas àquelas de LAJÚS (1997). No terceiro ano de fertilização nitrogenada na mesma área de campo natural de Planossolo, a resposta foi quadrática, conforme a equação $\mathrm{Y}=3.219,75+15,7058631 \mathrm{X}-$ $0,01541994 \mathrm{X}^{2}\left(\mathrm{R}^{2}=0,87\right)$ e o ponto de máxima produtividade de MS foi obtido com $509 \mathrm{~kg} / \mathrm{ha}$ de N. Esses três experimentos foram realizados nas estações de crescimento de 1992/93, 1993/94 e 1994/95, respectivamente, sob condições climáticas diferentes, entretanto mostram a mesma tendência e o elevado potencial de resposta do campo natural de Planossolo na produção de forragem em resposta à adubação nitrogenada. Neste experimento alcançou-se uma produção de, aproximadamente $9 \mathrm{~kg}$ de MS para cada $\mathrm{kg}$ de $\mathrm{N}$ aplicado, o que está de acordo com os resultados relatados por Davies e Willians (1958), citados por CARAMBULA (1977).

A análise de variância para os teores de proteína bruta do primeiro corte (Tabela 2) indicou significância apenas para os fatores principais, enxofre $(\mathrm{P}<0,05) \mathrm{e}$ nitrogênio $(\mathrm{P}<0,001)$, obtendo-se uma média geral de $8,22 \%$ de $\mathrm{PB}$ e $\mathrm{CV}=7,45 \%$. A análise de regressão polinomial para os níveis de enxofre indicou significância para o efeito linear com a seguinte equação de regressão $\mathrm{Y}=7,936310+0,0113143 \mathrm{X}$ $\left(\mathrm{R}^{2}=0,81\right)$ (Figura 3). Para os diferentes níveis de nitrogênio também houve significância para o efeito linear com a seguinte equação de regressão $\mathrm{Y}=6,785417+0,0114700 \mathrm{X}\left(\mathrm{R}^{2}=0,98\right)$ (Figura 4).

Para o segundo corte, a análise de variância para os teores de proteína bruta (Tabela 3) indicou significância tanto para o enxofre $(\mathrm{P}<0,01)$ quanto para o fator nitrogênio $(P<0,001)$, obtendo-se uma média geral de 5,77\% de $\mathrm{PB}$ e $\mathrm{CV}=7,10 \%$. A análise de regressão polinomial para os níveis de enxofre indicou significância para o efeito linear com a seguinte equação de regressão $Y=5,579107+0,0075607$ $\mathrm{X}\left(\mathrm{R}^{2}=0,54\right)$ (Figura 5). Para os diferentes níveis de nitrogênio também houve significância para o efeito linear com a seguinte equação de regressão $\mathrm{Y}=5,137708+0,0050433 \mathrm{X}\left(\mathrm{R}^{2}=0,99\right)($ Figura 6).

Os resultados obtidos indicam que a forragem de campo natural de Planossolo aumenta seu teor de proteína bruta, quando adubado com nitrogênio ou enxofre no início da primavera. Pela observação das equações de regressão ajustadas para o nitrogênio e o enxofre, não se obteve o ponto de máxima para o teor de proteína bruta na matéria seca da forragem em nenhum dos cortes neste experimento, já que a mesma foi linear dentro das doses de $\mathrm{N}$ e $\mathrm{S}$ usadas.
Tabela 2 - Teores médios de proteína bruta do primeiro corte, em \% MS, da forragem do campo natural nas diferentes doses de $\mathrm{N}$ e $\mathrm{S}$

Table 2 - Average crude protein contents of first cutting (\% DM) on different levels of $N$ and $S$

\begin{tabular}{lccccccc}
\hline $\mathrm{N}(\mathrm{kg} / \mathrm{ha})$ & \multicolumn{6}{c}{$\mathrm{S}(\mathrm{kg} / \mathrm{ha})$} & \\
\cline { 2 - 7 } & 0 & 10 & 20 & 30 & 40 & 50 & $\begin{array}{c}\text { Média } \\
\text { Mean }\end{array}$ \\
\hline 50 & 6,73 & 7,28 & 7,39 & 7,33 & 7,42 & 7,83 & 7,33 \\
100 & 7,90 & 8,23 & 8,11 & 7,98 & 7,95 & 8,05 & 8,04 \\
150 & 8,28 & 7,93 & 8,55 & 8,37 & 9,13 & 8,08 & 8,39 \\
200 & 8,92 & 8,30 & 9,03 & 9,24 & 9,59 & 9,65 & 9,12 \\
\hline $\begin{array}{l}\text { Média } \\
\text { Mean }\end{array}$ & 7,96 & 7,94 & 8,27 & 8,23 & 8,52 & 8,40 & 8,22 \\
\hline
\end{tabular}

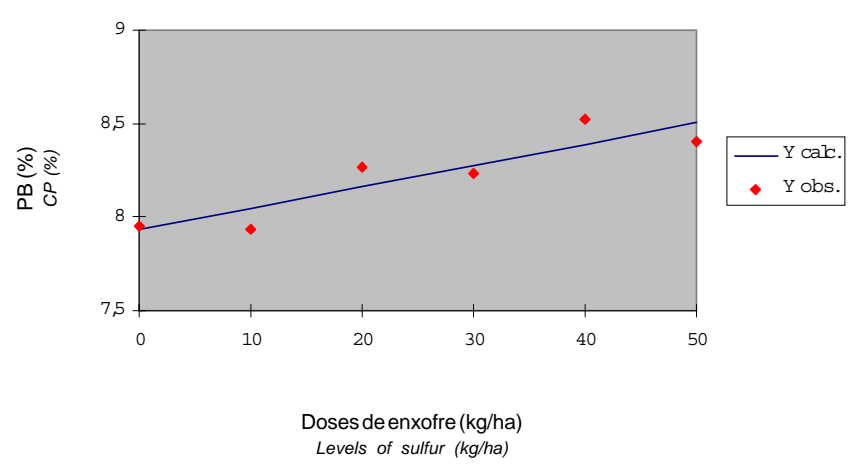

Figura 3 - Teor de proteína bruta na matéria seca da forragem, primeiro corte, em função das doses de enxofre.

Figure 3 - Crude protein contents (first cutting), according to levels of sulfur.

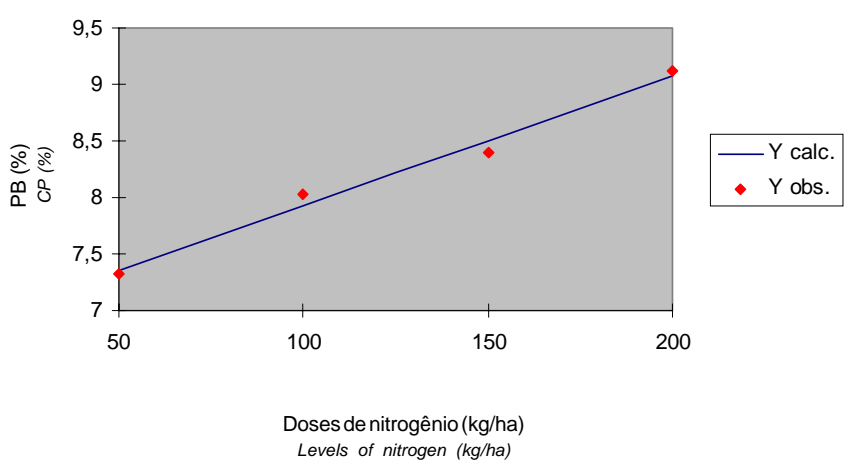

Figura 4 - Teor de proteína bruta na matéria seca da forragem, primeiro corte, em função das doses de nitrogênio.

Figure 4 - Crude protein contents (first cutting) according to levels of nitrogen. 
Rev. bras. zootec.

Tabela 3 - Teores médios de proteína bruta no segundo corte, em \%, da matéria seca da forragem do campo natural nas diferentes doses de $\mathrm{N}$ e $\mathrm{S}$

Table 3 - Crude protein contents in the second cutting (\%) on different levels of $N$ and $S$

\begin{tabular}{lccccccc}
\hline $\mathrm{N}(\mathrm{kg} / \mathrm{ha})$ & \multicolumn{7}{c}{$\mathrm{S} \mathrm{( \textrm {kg } / \mathrm { ha } )}$} \\
\cline { 2 - 7 } & 0 & 10 & 20 & 30 & 40 & 50 & $\begin{array}{c}\text { Média } \\
\text { Mean }\end{array}$ \\
\hline 50 & 5,11 & 5,12 & 5,69 & 5,38 & 5,71 & 5,16 & 5,36 \\
100 & 5,16 & 5,57 & 5,84 & 6,03 & 5,57 & 6,02 & 5,70 \\
150 & 6,05 & 5,51 & 5,74 & 6,03 & 5,94 & 5,97 & 5,87 \\
200 & 6,02 & 5,70 & 6,27 & 6,35 & 6,15 & 6,38 \\
Média & 5,59 & 5,48 & 5,89 & 5,95 & 5,84 & 5,88 & 5,15 \\
Mean & & & & & & &
\end{tabular}

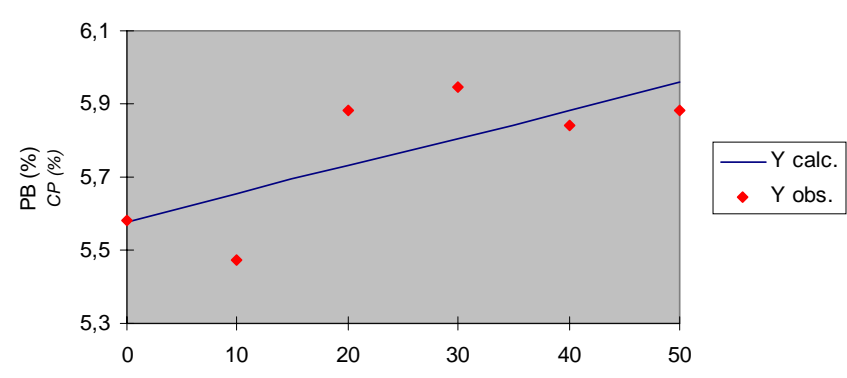

Figura 5 - Teor de proteína bruta na matéria seca da forragem, segundo corte, em função das doses de enxofre.

Figure 5 - Crude protein content (second cutting) according to levels of sulfur.

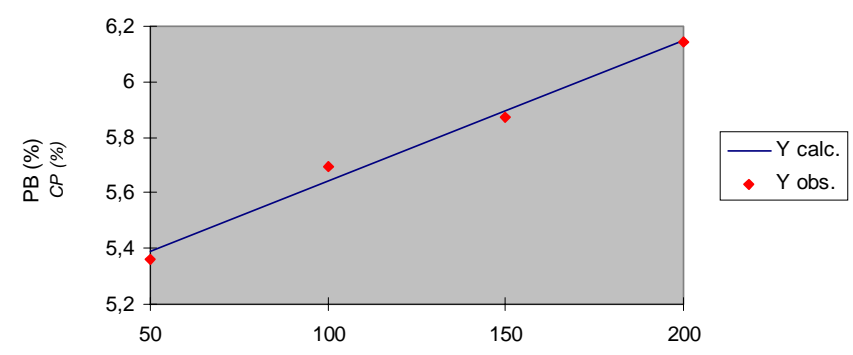

Figura 6 - Teor de proteína bruta na matéria seca da forragem, segundo corte, em função das doses de nitrogênio.

Figure 6 - Crude protein contents (second cutting) according to levels of nitrogen.
A este respeito, CARAMBULA (1977) cita em sua obra diversos autores que concluíram que o teor de proteína bruta na forragem aumenta de acordo com o nível de $\mathrm{N}$ aplicado ao solo. Apesar disso, o teor de proteína bruta na matéria seca da forragem é fundamentalmente dependente do momento em que se realiza o corte da pastagem. Essa tendência é verificada nesse experimento, quando se compara o teor de PB do primeiro com o teor do segundo corte, concluindo-se que o teor de PB da matéria seca da forragem diminui à medida que o período entre dois aproveitamentos consecutivos da pastagem é maior. Também deve-se destacar que a qualidade da forragem em termos de teor de PB é função, além do intervalo de crescimento da pastagem, da quantidade de $\mathrm{N}$ aplicado, da época em que é feito o corte e da espécie forrageira em questão.

Segundo GILLET (1984), para igual fertilização, existe um antagonismo entre os teores de PB e os rendimentos de MS. Este autor coloca que aumentos de MS diluem o N na planta. A diminuição do N provoca em muitos casos aumento da absorção, porém nunca é suficiente para compensar a diluição. Por isso, a igual fertilização, quanto mais produz ou cresce uma pastagem, menos rica em PB será. Nesta variação inversa entre o teor de $\mathrm{PB}$ e a produtividade de MS, sem dúvida os teores de PB é que variam menos, já que os aumentos na absorção compensam em parte os efeitos da diluição. Este antagonismo, sem dúvida, é função do tempo decorrido entre dois cortes sucessivos da pastagem. Corroborando este resultado, CARAMBULA (1977) afirma que, quanto maior o período de crescimento da forragem após a fertilização, maior será o efeito do $\mathrm{N}$ em aumentar a produtividade de MS e menor será o teor de PB da mesma. Dessa forma, a velocidade de absorção do $\mathrm{N}$ por parte das gramíneas é mais rápida que a resposta em crescimento. 


\section{Conclusões}

As fertilizações nitrogenada ou sulfurada aumentam a produção de matéria seca e o teor de proteína bruta da forragem do campo natural de Planossolo.

Doses de enxofre de, aproximadamente, $35 \mathrm{~kg} / \mathrm{ha}$ são suficientes para maximizar a produtividade de matéria seca do campo natural de Planossolo. Já doses de $200 \mathrm{~kg} / \mathrm{ha}$ de $\mathrm{N}$ não foram suficientes para determinar a máxima produção de matéria seca deste campo.

Doses de nitrogênio de até $200 \mathrm{~kg} / \mathrm{ha}$ e de enxofre de até $50 \mathrm{~kg} / \mathrm{ha}$ não foram suficientes para determinar o máximo teor de proteína bruta na forragem do campo natural de Planossolo.

\section{Referências Bibliográficas}

BITENCOURT JÚNIOR, D. Efeitos de doses de fósforo, potássio, calcário e suas interações na produção e qualidade da forragem do campo natural de Planossolo. Pelotas: UFPel, 1995. 117p. Dissertação (Mestrado) - Universidade Federal de Pelotas, Faculdade de Agronomia Eliseu Maciel, 1995.

BOIN, C. 1986. Produção animal em pastos adubados. In: Calagem e adubação de pastagens. Piracicaba-SP: Associação Brasileira para Pesquisa da Potassa e Fosfato. 476p.

CARAMBULA, M. 1977. Producción y manejo de pasturas sembradas. Montevídeo. Editoral Hemisfério Sur. 464p.

COMISSÃO DE FERTILIDADE DO SOLO-RS/SC. 1994. Recomendações de adubação e calagem para os Estados do Rio Grande do Sul e de Santa Catarina. 3.ed. Passo Fundo: SBCS-Núcleo Regional Sul. 223p.

COWLING, D.W., LOCKER, D.R. 1965. A comparison of the relation of diferent grass species to fertilizer nitrogen and to growth in association with withe clover. I. Yield to dry matter. J. Brit. Grassl. Soc., 20:197-204.

GALLO, J.R., HIROCE, R., BATAGLIA, O.C. et al. 1974. Composição química inorgânica de forrageiras no Estado de São Paulo. Bol. Ind. Anim., 31(1):115-38.

GILLET, M. Las gramíneas forrageiras. Zaragoza: Acriba. 355p. 1984.

GRIFFITH, W.K. 1974. Satisfying the nutritional requeriments of established legumes. In: MAYS, D.A. (Ed.). Forage fertilization. Madison. ASA-CSSA-SSSA. cap.7, p.147-170.

IBGE. 1986. Levantamento de recursos naturais. Rio de JaneiroRJ. Volume 33. Folha SH.21,22 e ST.22.

LAJÚS, C.A. Campo natural de planossolo: efeito da adubação nitrogenada na produção e qualidade da forragem. PelotasRS : UFPEL, 1995. 81 p. Dissertação (Mestrado em Zootecnia) - Faculdade de Agronomia "Eliseu Maciel"/Universidade Federal de Pelotas, 1995.
MALAVOLTA, E. 1979. Absorção e transporte de íons e nutrição mineral. In: FERRI, M.G. (Ed.) Fisiologia vegetal 1. São Paulo. USP. p.77-113.

MASCARENHAS, H.A.A. 1977. Cálcio, enxofre e ferro no solo e na planta. Fundação Cargill. 95p.

MONTEIRO, F.A. Sulfur fertilization and nutrient distribution in a Florida spodosol profile under white clover - pensacola bahiagrass. Gainsville: University of Florida, 1986. 182p. (Ph.D. Dissertation), University of Florida, 1986.

NUNES, A.P. Efeito de doses crescentes de nitrogênio na produção e qualidade da forragem de um campo natural de Planossolo no Rio Grande do Sul. Pelotas-RS: UFPEL, 1995. 96p. Dissertação (Mestrado em Zootecnia) - Faculdade de Agronomia "Eliseu Maciel"/Universidade Federal de Pelotas. 1995.

PUPO, N.I.H. 1979. Manual de pastagens e forrageiras: formação, conservação, utilização. Campinas-SP: Instituto Campineiro de Ensino Agrícola. 343p.

RAIJ, B.V. 1991. Fertilidade do solo e adubação. Piracicaba-SP. CERES, POTAFOS. 343p.

REID, D. The response of herbage yields and quality to a wide range of nitrogen application rates. In: INTERNATIONAL GRASSLAND CONGRESS, 10, 1966, Helsinki. Proceedings... Helsinki, 1966. p.209-213.

SIEBERT, B.D., VIJCHULATA, P. 1983. Sulfur in animal nutrition. In: BLAIR, G.J., TILL, A.R. (Eds.) Sulfur in S.E. Asian and S. Pacific agriculture. Armidale: University of New England. p.87-96.

SILVA, R.M. Efeito de doses e do fracionamento do nitrogênio na produção e qualidade da forragem de campo natural de Planossolo, visando a produção de feno. Pelotas-RS: UFPEL, 1995. 151p. Dissertação (Mestrado em Zootecnia) Faculdade de Agronomia "Eliseu Maciel"/Universidade Federal de Pelotas, 1995.

TEIXEIRA, L.I.O. Potencial de produção e qualidade da forragem do campo natural de Planossolo, visando a produção de feno, sob diferentes doses e fracionamentos do nitrogênio. Pelotas-RS : UFPEL, 1995. 120p. Dissertação (Mestrado em Zootecnia) - Faculdade de Agronomia "Eliseu Maciel"/ Universidade Federal de Pelotas, 1995.

TISDALE, S.L. Sulfur in forage quality and ruminant nutrition. Washington, DC, The Sulfur Institute. 13p. (Technical Bulletin, 22). 1977.

WILKINSON, S.R., LANGDALE, G.W. 1974. Fertility needs of the warm-season grasses. In: MAYS, D.A.(Ed.). Forage fertilization. Madison. ASA-CSSA-SSSA. cap. 6, p.119-146.

ZONTA, E.P., MACHADO, A.D. 1984. SANEST - Sistema de análise estatística para microcomputadores. Pelotas-RS. UFPEL. 75p.

Recebido em: 25/10/99

Aceito em: 07/01/01 